\title{
Characterization of Leishmania infection in rodents from endemic areas of the Islamic Republic of Iran
}

M. Mohebali, ${ }^{1}$ E. Javadian, ${ }^{1}$ M.R. Yaghoobi-Ershadi, ${ }^{1}$ A.A. Akhavan, ${ }^{1}$ H. Hajjaran ${ }^{1}$ and M.R. Abaei'

$$
\begin{aligned}
& \text { خحصائص عدوى القوارض بالليشمانيات في المناطق الموطونة بها في جمهورية إيران الإسلامية }
\end{aligned}
$$

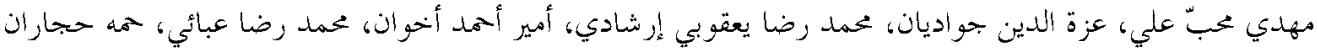

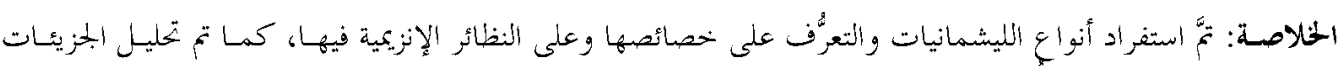

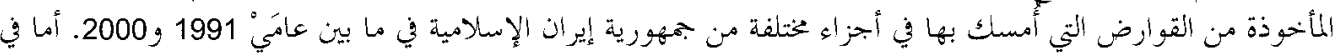

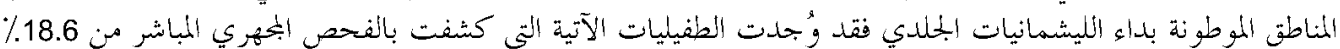

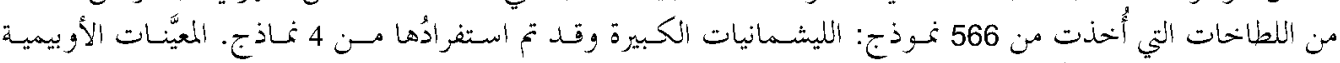

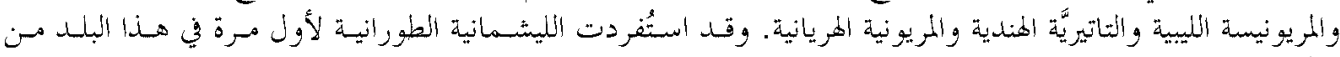

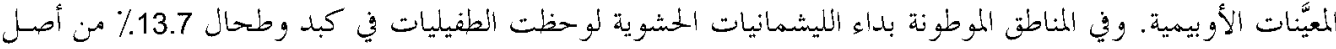

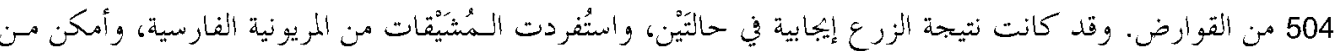

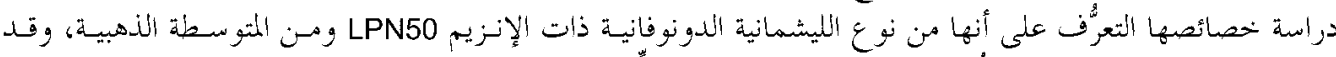

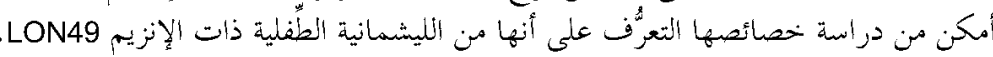

ABSTRACT Between 1991-2000, Leishmania species were isolated and characterized by isoenzyme and molecular analysis from rodents caught in various parts of the Islamic Republic of Iran. In areas endemic for cutaneous leishmaniasis, parasites were observed by direct microscopy in smears from $18.6 \%$ of 566 specimens. L. majorwas isolated from 4 species: Rhombomys opimus, Meriones libycus, Tatera indica and Mer. hurrianae. L. turanica was isolated from $R$. opimus for the first time in this country. In endemic areas of visceral leishmaniasis, parasites were observed in liver and spleen from $13.7 \%$ of 504 rodents. Two species were positive on culture; promastigotes isolated from Mer. persicus were characterized as $L$. donovani zymodeme LON50 and from Mesocricetus auratus as L. infantum LON49.

Caractérisation de l'infection à Leishmania chez des rongeurs des zones endémiques de la République islamique d'Iran.

RÉSUMÉ Entre 1991 et 2000, des espèces de Leishmania ont été isolées et caractérisées par isoenzymes et analyse moléculaire chez des rongeurs capturés dans diverses parties de la République islamique d'Iran. Dans les zones d'endémie de la leishmaniose cutanée, des parasites ont été observés par microscopie directe dans des frottis provenant de $18,6 \%$ des 566 échantillons. L. majora été isolé chez quatre espèces : Rhombomys opimus, Meriones libycus, Tatera indica et Mer. hurrianae. L. turanica a été isolé chez R. opimus pour la première fois dans ce pays. Dans les zones d'endémie de la leishmaniose viscérale, des parasites ont été observés dans le foie et la rate de $13,7 \%$ des 504 rongeurs. Deux espèces ont donné des cultures positives ; les promastigotes isolés chez Mer. persicus ont été caractérisés comme zymodème LON50 de L. donovaniet ceux isolés chez Mesocricetus auratus comme LON49 de L. infantum.

'School of Public Health and Institute of Public Health Research, Tehran University of Medical Sciences, Tehran, Islamic Republic of Iran.

Received: 14/04/03; accepted: 26/10/03

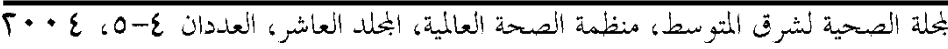




\section{Introduction}

Leishmaniasis is an important health problem in the Islamic Republic of Iran. There are several foci of zoonotic cutaneous leishmaniasis (CL) in the north, east and south of the country [1-6]. Zoonotic CL is essentially a disease of gerbils, transmitted by Phlebotomus papatasi and $P$. cocausicus and other species of sand fly that breed in gerbil burrows [7]. The human disease is secondary to the infection of gerbils and is seen only in places where the infected gerbils live [8]. Three different epidemiological types of zoonotic CL have been observed in this country and 4 species of rodents (Gerbillidae) are the principal animal reservoir hosts in all foci [9].

Visceral leishmaniasis (VL), or kala-azar, is also seen sporadically all over the Islamic Republic of Iran and is of the Mediterranean type. Wild and domestic carnivores are the main animal reservoirs [10-12], but rodents have been reported as reservoirs in the Meshkin-Shar district [13]. Sand flies of the genus Phlebotomus are the most likely vector of $\mathrm{VL}$ in the endemic areas [10].

The study of Leishmania infection in rodents in the Islamic Republic of Iran started in 1953 in the north-east of the country [8] but, while it was extended to other parts of the country, the isolation and characterization of the parasites has not been investigated in these areas. In this study, we report the isolation and characterization of Leishmania species infection from a number of species of rodents that were trapped alive in different parts of the Islamic Republic of Iran in the last decade.

\section{Methods}

\section{Study area}

The investigation was conducted over a period of 10 years from 1991 to 2000 in endemic foci of zoonotic CL and VL in the Islamic Republic of Iran (Figure 1).

\section{Collection and examination of rodents}

The study sites were determined by reports from local health authorities of outbreaks of human CL and VL infection. The active colonies of rodents were identified and the rodents were trapped alive in various parts of these areas. Specimens were collected from the colonies of gerbils located about $1-1.5 \mathrm{~km}$ around villages where CL or VL were endemic. Around 20-30 live traps were used each week and rodents were caught in all seasons. The genus and species of the rodents were determined by external characteristics: colour, body measurements, ears, tail, feet, teeth and cranium $[14,15]$.

\section{Isolation of parasites from the caught rodents}

For detecting CL infection, 2 impression smears were taken from the ears of each rodent $[13,16]$. For detecting VL parasites, 2 impression smears from the spleen and liver of each rodent were prepared. The smears were fixed in methanol, stained by standard Giemsa methods and examined for parasites by light microscope at high magnification $(\times 1000)$.

The samples from infected rodents were cultured in Novy-MacNeal-Nicolle (NNN) culture and liver infusion broth tryptose (LIT) and RPMI 1640 medium (Gibco Life Technologies, New York, USA) containing $10 \%$ heat-inactivated fetal calf serum. The cultures were checked for promastigotes twice a week for a period of 6 weeks.

Leishmania species were characterized by random amplified polymorphic DNApolymerase chain reaction (RAPD-PCR)

البحلة الصحية لشرق المتو سط، منظمة الصحة العالمية، البحلد العاشر، العددان ع-0، ع + • 


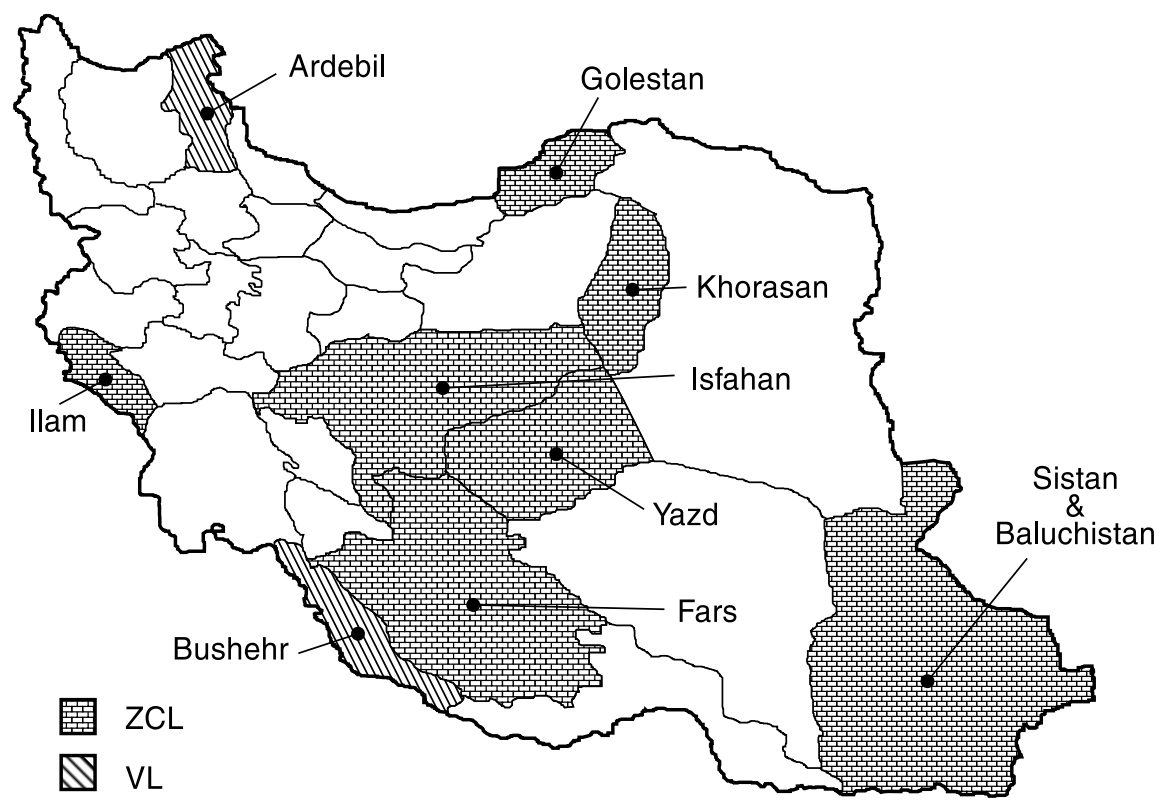

Figure 1 Areas endemic for zoonotic cutaneous leishmaniasis (ZCL) and visceral leishmaniasis (VL) where rodents were collected for the study

analysis $[17,18]$ at the Medical Faculty, Shiraz University of Medical Sciences and the School of Pubic Health, Tehran University of Medical Sciences and by isoenzyme analysis at the London School of Hygiene and Tropical Medicine, United Kingdom, and the Faculty of Medicine, University of Montpellier, France.

\section{Characterization of isolated parasites}

For the RAPD-PCR analysis, DNA was extracted from the promastigotes, cultured at $20{ }^{\circ} \mathrm{C}$ in RPMI1640 medium (10 000 parasites per $10 \mathrm{~mL}$ ) and washed with Locke's solution. The pellet was resuspended in $100 \mu \mathrm{L}$ lysis buffer. The lysate was extracted once with equal volumes of 1:1 (v/v) phenol:chloroform and once with
24:1 (v/v) chloroform isoamylalcohol and precipitated by ethanol. The DNA was resuspended in the specified materials and amplification were done in a mixture containing $20 \mathrm{mmol} / \mathrm{L}\left(\mathrm{NH}_{4}\right)_{2}\left(\mathrm{SO}_{4}\right), 75 \mathrm{mmol} / \mathrm{L}$ Tris-HCl, pH.9, 0.01\% (w/v) Tween 20, 2 $\mathrm{mmol} / \mathrm{L} \mathrm{MgCl}, 200 \mu \mathrm{mol} / \mathrm{L}$ deoxynulcleotide triposphate, $1 \mathrm{mmol} / \mathrm{L}$ primer and 1 unit of Taq polymerase. Then $1 \mu \mathrm{L}$ of DNA (20 $\mathrm{ng} / \mu \mathrm{L}$ ) was added by centrifugation through the mineral oil overlay and the reaction was carried out in a thermocycler (Genius, Techne Ltd, United Kingdom) programmed for 1 cycle of 2 min at $94^{\circ} \mathrm{C}$, followed by 30 cycles of $30 \mathrm{~s}$ at temperatures of $94{ }^{\circ} \mathrm{C}, 1 \mathrm{~min}$ at $36^{\circ} \mathrm{C}$ and 2 min at $72{ }^{\circ} \mathrm{C}$. Aliquots from each reaction $(12 \mu \mathrm{L})$ were run on $1.5 \%$ agarose gel and visualized under ultraviolet light with ethidium

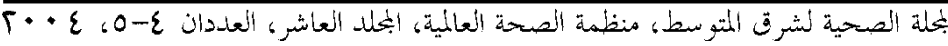


bromide. The primers used in this study were as follows:

- AB1-07 GGT GAC GCA G

- 327. ATA CGG CGT C

- 329. GCG AAC CTC C

- 333. GAA TGC GAC G

- 335. TGG ACC ACC C

For the isoenzyme characterization, after mass production of promastigotes, samples were cultured in monophasic media with $10 \%$ to $20 \%$ fetal calf serum, washed with phosphate-buffered saline at $4{ }^{\circ} \mathrm{C}$ with centrifugation at $2500-3000 \times \mathrm{g}$ for $20 \mathrm{~min} 3$ times and freeze-thawed in liquid nitrogen several times, followed by electrophoresis on polyacrylamide gel. In this technique 12 enzymes were used: pyruvate kinase (PK), superoxide dismutase (SOD), phosphoglucomutase (PGM), peptidase D (PEPD), alanine aminotransferase (ALT), aspartate aminotransferase (AST), nucleoside hydrolase ( $\mathrm{NH})$, glucose-6-phosphate dehydrogenase (G6PD), glucose-6-phosphate isomerase (GPI), esterase (ES), methanol dehydrogenase $(\mathrm{MDH})$ and mannose-6-phosphate isomerase (MPI) [19].

\section{Results}

\section{Areas endemic for cutaneous leishmaniasis}

Altogether, 566 rodents (Gerbillidae) were trapped alive in several CL-endemic areas throughout the Islamic Republic of Iran from 1991 to 2000. Leishmania parasites were observed in cutaneous smears from $105(18.6 \%)$ of the rodents by direct high magnification microscopy examination (Table 1).

L. major was isolated from Rhombomys opimus, Meriones libycus, Tatera indica and Mer. hurrianae and characterized by isoenzyme analysis and molecular procedures (RAPD-PCR). All of the Leishmania species and strains were similar to Leishmania species that had been isolated from human infection in the same areas. $L$. $t u$ ranica was isolated from an infected $R$. opimus for the first time in this country.

$R$. opimus was the principal reservoir host of zoonotic CL in the north-eastern (Minoo Dasht) district where $85.2 \%$ of isolates tested positive (Table 1). It was also prominent in the central parts of the country (Badrood, Ardakan and Sabzevar districts). Mer. libycus was found in $35.1 \%$ of isolates in the south-west (Fars province) and $25.0 \%$ in the central area. T. indica was the main reservoir host in foci of the south-west (14.3\%) and south (Dashti and Dashtestan districts) of the country $(4.5 \%$ of isolates tested positive). In the southeast of the country (including southern parts of Baluchistan, Dashtyari, Konarak and Chabahar areas) the main animal reservoir was Mer. hurrianae (17.9\% of isolates).

\section{Areas endemic for visceral leishmaniasis}

A further 504 rodents (Gerbillidae, Cricetidae) were caught during 1994 to 2000 in 2 areas endemic for VL: Meshkin-Shahr district (north-west) and Dashti and Dashtestan districts (south). Leishmania parasites were seen in livers and spleens of 69 $(13.7 \%)$ of these rodents by microscopy (Table 2).

Leishmania spp. were isolated from 2 specimens of Mer. persicus and 1 specimen of Mesocricetus auratus in culture media (Table 2). Although parasites were observed in a few specimens of Cricetulus migratorius, none were positive on culture. Using isoenzyme techniques the promastigotes isolated from Mer. persicus were characterized as $L$. donovani zymodeme

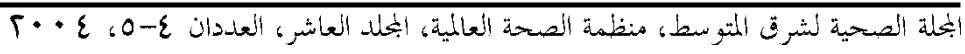


Table 1 Leishmania species isolates from rodents caught in areas of the Islamic Republic of Iran endemic for cutaneuos leishmaniasis (1991-2000)

\begin{tabular}{|c|c|c|c|c|}
\hline $\begin{array}{l}\text { Location of capture/ } \\
\text { rodent species }\end{array}$ & $\begin{array}{l}\text { No. } \\
\text { tested }\end{array}$ & \multicolumn{2}{|c|}{$\begin{array}{l}\text { Positive on } \\
\text { microscopy }\end{array}$} & $\begin{array}{l}\text { Leishmania } \\
\text { species } \\
\text { identified }\end{array}$ \\
\hline \multicolumn{5}{|l|}{$\begin{array}{l}\text { North-east (Minoo Dasht } \\
\text { district) }\end{array}$} \\
\hline Rhombomys opimus & 27 & 23 & 85.2 & L. major \\
\hline Meriones libycus & 1 & 0 & 0 & - \\
\hline \multicolumn{5}{|l|}{$\begin{array}{l}\text { South (Dashti and } \\
\text { Dashtestan district) }\end{array}$} \\
\hline Tatera indica & 133 & 6 & 4.5 & L. major \\
\hline Meriones crassus & 48 & 0 & 0 & - \\
\hline Rattus rattus & 3 & 0 & 0 & - \\
\hline Nesokia indica & 3 & 0 & 0 & - \\
\hline Mus musculus & 5 & 0 & 0 & - \\
\hline \multicolumn{5}{|l|}{ South-east (Baluchestan) } \\
\hline Meriones hurrianae & 28 & 5 & 17.9 & L. major \\
\hline Tatera indica & 27 & 1 & 3.7 & - \\
\hline Rattus rattus & 3 & 0 & 0 & - \\
\hline Rattus norvegicus & 4 & 0 & 0 & - \\
\hline Mus musculus & 5 & 0 & 0 & - \\
\hline Nesokia indica & 2 & 0 & 0 & - \\
\hline Funambulus pennanti & 1 & 0 & 0 & - \\
\hline \multicolumn{5}{|l|}{ West (Mehran district) } \\
\hline Tatera indica & 22 & 2 & 9.1 & L. major \\
\hline Nesokia indica & 8 & 0 & 0 & - \\
\hline \multicolumn{5}{|l|}{ Central (Badrood district) } \\
\hline Meriones libycus & 36 & 9 & 25.0 & L. major \\
\hline Rhombomys opimus & 25 & 8 & 32.0 & L. major \\
\hline \multicolumn{5}{|c|}{ South-west (Fars province) } \\
\hline Meriones libycus & 97 & 34 & 35.1 & L. major \\
\hline Tatera indica & 21 & 3 & 14.3 & - \\
\hline \multicolumn{5}{|l|}{ Central (Ardakan district) } \\
\hline Rhombomys opimus & 26 & 3 & 11.5 & L. major \\
\hline Meriones libycus & 19 & 3 & 15.8 & - \\
\hline \multicolumn{5}{|c|}{ Central (Sabzevar district) } \\
\hline Rhombomys opimus & 22 & 8 & 36.4 & $\begin{array}{l}\text { L. majorand } \\
\text { L. turanica }\end{array}$ \\
\hline Total & 566 & 105 & 18.6 & \\
\hline
\end{tabular}

المحلة الصحية لشرق المتوسط، منظمة الصحة العالمية، البحلد العاشر، العددان ع-0، ع • • 
LON50 and those from Mes. auratus were identified as L. infantum LON49.

\section{Discussion}

Both CL and VL are endemic in the Islamic Republic of Iran. Mucosal leishmaniasis is usually an extension of the cutaneous form, except for 3 cases of lesions of the palate for which the causative organisms are unknown [20].

The cutaneous form of leishmaniasis is seen in 2 forms: anthroponotic and zoonotic. Anthroponotic CL is endemic in many large- and medium-size cities, as well as villages in the suburbs of these foci. The main reservoir host of CL is man, although the lesions have been observed on dogs in Tehran, Mashad, Shiraz and Kerman [9]. Zoonotic CL is endemic in many foci in the north, east and south of the country [9]. This is essentially a disease of gerbils, transmitted by sand flies that live and breed in the gerbil burrows. The human disease is secondary to the infection of gerbils and is seen only in places where the infected gerbils live.

Our results show that $R$. opimus (great gerbil) is the principal reservoir host of zoonotic CL in the central and north-east parts of the country. Mer. libycus (Libyan jird) was also found to be infected and can act as a secondary reservoir host in the absence of $R$. opimus. Of course, in some areas from the centre and south of the country, gerbils have become the primary reservoir of zoonotic CL due to ecological changes [21]. Other foci are in TurkemenSahara, Lotfabad and Sarakhs, that is the border with Turkemenistan Republic, Esfarayen in Khorasan, Bakran in Semnan, Abarkuh in Yazd, Neiriz and Estahban in Fars provinces. Natural Leishmania spp. infection of $R$. opimus is found in Abardej of Varamin near Tehran but far from human residences and Leishmania species have not yet been determined [9,22].

$T$. indica (Indian jird) is the main reservoir host of zoonotic CL in foci of the south-west and south of the country.

\begin{tabular}{|c|c|c|c|c|c|c|}
\hline \multirow[t]{2}{*}{$\begin{array}{l}\text { Location of capture/ } \\
\text { rodent species }\end{array}$} & \multirow[t]{2}{*}{$\begin{array}{l}\text { No. } \\
\text { tested }\end{array}$} & \multicolumn{2}{|c|}{$\begin{array}{l}\text { Positive on } \\
\text { microscopy }\end{array}$} & \multicolumn{2}{|c|}{$\begin{array}{l}\text { Positive on } \\
\text { culture media }\end{array}$} & \multirow{2}{*}{$\begin{array}{l}\text { Leishmania species } \\
\text { and zymodemes } \\
\text { identified }\end{array}$} \\
\hline & & No. & $\%$ & No. & $\%$ & \\
\hline \multicolumn{7}{|l|}{ Meshkin-Shahr } \\
\hline Cricetulus migratorius & 15 & 2 & 13.3 & 0 & 0 & - \\
\hline Mesocricetus auratus & 2 & 1 & 50.0 & 1 & 50.0 & L. infantum LON49 \\
\hline Meriones persicus & 394 & 66 & 16.8 & 2 & 0.5 & L. donovaniLON50 \\
\hline Mus musculus & 7 & 0 & 0 & 0 & 0 & - \\
\hline Allactaga spp. & 1 & 0 & 0 & 0 & 0 & - \\
\hline \multicolumn{7}{|l|}{$\begin{array}{l}\text { Dashti and Dashtestan } \\
\text { district }\end{array}$} \\
\hline Tatera indica & 85 & 0 & 0 & 0 & 0 & - \\
\hline Total & 504 & 69 & 13.7 & 3 & 0.6 & \\
\hline
\end{tabular}

لبلة الصحية لشرق المتوسط، منظمة الصحة العالمية، المجلد العاشر، العددان ع-0، ع + •؟ 
These areas include the Iran-Iraq borders from Sumar to the Gulf, all the provinces of Khuzestan and some parts of Ilam, Bushehr and Hormozegan $[1,11,23]$.

In foci of the south-east of the country, the main animal reservoir is Mer. hurrianae (Indian desert jird). These areas include the southern parts of Baluchistan, Dashtyari, Konarak and Chabahar areas. This type of zoonotic CL is similar to the foci of the disease reported from Rajasthan in India $[4,7,9]$.

The visceral form of leishmaniasis is seen in sporadic form all over the Islamic Republic of Iran and is endemic in Ardebil and east Azerbaijan provinces in the northwest, and in Fars and Bushehr in the south. Wild and domestic dogs are the main reservoir hosts of VL [12]. In this study, amastigotes were observed in $13.7 \%$ of the rodents on microscopic examination of the smears prepared from internal organs.

L. donovani LON-50 was isolated from 2 specimens of Mer. persicus (Persian jird). It seems to transmit from infected rodents to humans in these endemic areas. $L$. infantum LON-49 was isolated from 1 specimen of Mes. auratus (golden hamster). This species of Leishmania is zoonotic and had been previously isolated from humans [10] and dogs in the Meshkin-Shahr area [12], and also from dogs and foxes in the Dashti district of Bushehr province [11]. $L$. infantum had been isolated from Rattus rattus (black rat) in Italy and Iraq [24]. In one study, Mer. persicus was reported to be naturally infected with Leishmania spp. in east Azerbaijan, in the north-west of the Islamic Republic of Iran. In the smears prepared from the cutaneous lesion of this gerbil, considerable numbers of amastigotes were seen. However, microscopic examination of the smears prepared from the internal organs and blood of this rodent did not show any amastigotes [25]. In the other study that was carried out in the Semeskandeh area of Mazanderan province in the north of the Islamic Republic of Iran, Leishmania spp. infection was reported in internal organs of $R$. rattus but Leishmania parasites were not isolated from them (Gholami, personal communication).

In conclusion, this study has shown that rodents harbour Leishmania spp. infection and may therefore have a role in transmission of leishmaniasis to humans, particularly to children. Further ecological and biological studies of rodents and sand flies are necessary in endemic foci of zoonotic VL from the Islamic Republic of Iran until the exact role of the rodents as animal reservoirs is clarified completely.

\section{Acknowledgements}

We are very grateful to the field staff of the provincial health department of Isfahan, Golestan, Bushehr, Baluchistan, Ilam, Fars and Yazd provinces. The authors would like to thank Dr D. Evans and Dr S. Mazlumi from the London School of Hygiene and Tropical Medicine; Dr J.P. Dedet from Montpellier, France, for isoenzyme characterization of the Leishmania isolates; and Dr K.P. Chang from Chicago University, USA, and student Kayako for performing PCR-RFLP. Thanks are also due to Dr Y. Hamzavi and Dr H. Kathiri for field activities. This investigation was supported by the School of Public Health and Institute of Public Health Research, Tehran University of Medical Sciences.

المحلة الصحية لشرةق المتو سط، منظمة الصحة العالمية، المجلد العاشر، العلددان ع-0، ع • • 


\section{References}

1. Javadian $\mathrm{E}$ et al. Reservoir host of cutaneous leishmaniasis in Iran [Abstract]. Proceedings of the XIIth International Congress of Tropical Medicine and Malaria. Amsterdam, The Netherlands, 1823 September, 1988.

2. Nadim A, Seyedi-Rashti MA, Mesghali A. Epidemiology of cutaneous leishmaniasis in Turkemen Sahara, Iran. Journal of tropical medicine and hygiene, 1968, $71: 238-9$.

3. Nadim A, Seyedi-Rashti MA. A brief review of the epidemiology of various types of leishmaniasis in Iran. Acta medica iranica, 1971, XIV:99-106.

4. Seyedi-Rashti MA et al. Cutaneous leishmaniasis in Baluchistan, Iran [Abstract and Poster]. Proceedings of the XI International Congress of Tropical Medicine and Malaria. Calgary, Canada, 1622 September, 1984.

5. Yaghoobi-Ershadi MR et al. Epidemiology study in a new focus of cutaneous leishmaniasis due to Leishmania major in Ardestan town, Central Iran. Acta tropica, 2002, 79:115-21.

6. Hamzavi $Y$ et al. Epidemiological studies of cutaneous leishmaniasis (human infection, animal reservoirs) in Dashti and Dashtestan districts, Bushehr province. Iranian public health, 2000, 29(1-4): 177-91.

7. Control of the leishmaniases. Report of a WHO Expert Committee. Geneva, World Health Organization, 1990:1-158 (WHO Technical Report Series, No. 793).

8. Nadim A, Faghih M. The epidemiology of cutaneous leishmaniasis in the Isfahan province of Iran. I. The reservoir. II. The human disease. Transactions of the Royal Society of Tropical Medicine and Hygiene, 1968, 62:534-42.
9. Nadim A. Leishmaniases. In: Azizi F et al., eds. Epidemiology and control of prevalent diseases in Iran, 2nd ed. Isfahan, Iran, Endocrine and Metabolism Research Centre, 2000:524-34 [in Farsi].

10. Edrissian GhH et al. Visceral leishmaniasis: the Iranian experience. Archives of Iranian medicine, 1998, 1(1):22-6.

11. Mohebali $M$ et al. Seroepidemiological study of visceral leishmaniasis among humans and animal reservoirs in Bushehr province, Islamic Republic of Iran. Eastern Mediterranean health journal, 2001, 7:912-7.

12. Mohebali M et al. Study on canine visceral leishmaniasis in the various parts of Iran. Veterinary journal of Tehran University, 2001, 56(3):55-9.

13. Mohebali $\mathrm{M}$ et al. Rodents: another group of animal reservoir hosts of visceral leishmaniasis in Meshkin-Shahr district, the Islamic Republic of Iran. Eastern Mediterranean health journal, 1998, 4(2):376-8.

14. Ziaei $\mathrm{H}$. A field guide for identifying of Iranian desert mammalians, 1 st ed. Tehran, Iran, Iranian Environment Organization, 1996:129-87.

15. Boitani L, Bartoli S. Macdonald encyclopedia of mammals. London, Macdonald \& Co., 1980.

16. Edrissian GH, Zovein Z, Nadim A. A simple technique for preparation of smears from the ear of Rhombomys opimus for the detection of leishmanial infection. Transactions of the Royal Society of Tropical Medicine and Hygiene, 1982, 76:706-7.

17. Noyes HA, Belli AA, Maingon R. Appraisal of various RAPD-PCR primers 
for Leishmania identification. American journal of tropical medicine and hygiene, 1996, 55(1):98-105.

18. Motazedian $\mathrm{H}$, Noyes $\mathrm{H}$, Maingon $\mathrm{R}$. Leishmania and sauroleishmania: the use of random amplified polymorphic DNA for identification of parasites from vertebrates and invertebrates. Experimental parasitology, 1996, 83:150-4.

19. Evans DB. Handbook on isolation, characterization and cryopreservation of Leishmania. UNDP/World Bank/WHO Special Programme for Research and Training in Tropical Diseases. Geneva, World Health Organization, 1989:1432.

20. Yaghoobi MR et al. Mucosal leishmaniasis: report of three cases. Archives of Iranian medicine, 2001, 4(3):138-40.

21. Yaghoobi-Ershadi MR, Akhavan AA, Mohebali M. Meriones libycus and Rhombomys opimus (Rodentia: Gerbillidae) are the main reservoir hosts in a new focus of zoontic cutaneous leishmaniasis in Iran. Transactions of the Royal Society of Tropical Medicine and Hygiene, 1996, 90(5):503-4.
22. Seyedi-Rashti MA et al. A new focus of zoonotic cutaneous leishmaniasis near Tehran, Iran. Proceedings of the VIIth International Congress of Parasitology, Paris, France, 20-24 August. Bulletin de la Societe Francaise de Parasitology, 1990, (suppl.)2:1145.

23. Javadian E et al. Confirmation of Tatera indica (Rodentia:Gerbillidae) as the main reservoir host of zoonotic cutaneous leishmaniasis in the west of Iran. Iranian journal of public health, 1998, 27(1-2):55-60.

24. Desjeux P. Information of epidemiology and control of the leishmaniases by country or territory. Geneva, World Health Organization, 1991 (WHO/ LEISH/91.30).

25. Edrissian $\mathrm{GH}$, Ghorbani M, TahvildarBidruni G. Meriones persicus, another probable reservoir of zoonotic cutaneous leishmaniasis in Iran. Transactions of the Royal Society of Tropical Medicine and Hygiene, 1975, 69(5-6):517-9.

المحلة الصحية لُشرق المثتو سط، منظمة الصحة العالمية، المجلد العاشر، العددان ع-0، ع • • 